\title{
UJI PERFORMA SEPEDA MOTOR SPORT SISTEM PROGRAMMED FUEL INJECTION (PGM-FI) SATU SILINDER 150 CC MENGGUNAKAN BAHAN BAKAR BENSIN RON 92
}

\author{
Amir $^{(1)}$, Muhammad Nofriansyah ${ }^{(2)}$ \\ Program Studi Teknik Mesin, Fakultas Teknik, Universitas Muhammadiyah Tangerang \\ Jl. Perintis Kemerdekaan I/33 Cikokol-Tangerang \\ Email : ${ }^{1 .}$ amirduta815@gmail.com
}

\begin{abstract}
ABSTRAK
Mesin mobil maupun motor memerlukan jenis bensin yang sesui dengan desain mesin itu sendiri agar dapat bekrja dengan baik dan menghasilkan kinerja yang optimal. Perlu diketahui bahwa setiap jenis mobil ataupun sepeda motor memiliki spesifikasi mesin yang berbeda-beda. Pada brosur yang baik akan menampilkan informasi rasio kompresi. Sepeda motor merupakan pengembangan dari sepeda komvensional yang lebih dahulu ditemukan. Pada tahun 1868 oleh michaux ex cie. Suatu perusahaan yang memproduksi sepeda pada jaman sekarng, mulai mengembangkan teknologi fuel injection sebagai sistem bahan bakar sepeda motor.Berdasarkan hasil pengujian motor dengan bahan bakar pertamax menunjukan konsumsi bahan bakar paling irit. Hasil pengukuran tingkat konsumsi bahan bakar pada shell super. Dan berdasarkan kecepatan putaran mesin 2500 rpm menunjukan hasil yang lebih irit konsumsi bahan bakarnya
\end{abstract}

Kata kunci : Sepeda Motor, Fuel Injection, Pertamax, Shell super.

Teknik otomotif adalah salah satu cabang ilmu teknik mesin yang mempelajari tentang bagaimana merancang, membuat dan mengembangkan alat-alat transportasi darat yang menggunakan mesin,

Bahan bakar merupakan energi dari hasil bumi yang dapat berupa cairan, gas dan juga padat, energi yang menghasilka bahan bakar adalah kandungan panas yang dilepas. Kebanyakan bahan bakar yang digunakan oleh kendaraan bermotor adalah jenis proses pembakaran dimana-mana bahan bakar tersebut akan melepaskan panas bercampur dengan oksigen dan perapian, Setiap kendaraan memiliki bahan bakar yang berbeda-beda dan juga spesifikasi mesin yang

Energi yang dapat diberikan pun dapat mengoptimalkan kinerja pada mesin. Dan efisien dalam pemakai bahan bakar pengaruh terhadap kineja mesin karena nilai bahan bakar cairan adalah oktan daribahan bakar tersebut, mempengaruhi nilai dan kemampuan dari tenaga yang dihasilkan, masing-masing dari bahan bakar cair memiliki kandungan oktan yang berbeda-beda

\section{Teknologi Otomotif}

Teknologi Otomotif menjadi semakin penting untuk dikuasai dan dikembangkan. Sumber daya manusia yang mampu mengusai dan mengembangkan teknologi Otomotif makin dibutuhkan. Maka dengan perkembangan ilmu dan teknologi dan meningkatkan baik kualitas maupun kuantitas dari produk Teknologi. terutama sepeda motor, mobil, bis dan truk. Teknik otomotif menggabungkan elemen-elemen pengetahuan mekanika, listrik, elektronik, keselamatan dan lingkungan serta matematika, fisika, kimia, biologi dan manajemen.

\section{Sejarah Sepeda Motor}

Meskipun tenga uap telah menjadi sumberdaya yang efisien sampai pada tahun 1800sanmenggunakan tenaga uap untuk kendaraan jalan raya masih terbatas, tahun 1860 perekayasa asal Prancis Etienne Lenoir tercatat sebagai orang pertama yang merancang mesin pembakaran intenal. Karena pembakarannya menempelkan salah satu mesin itu pada kendaraan yang kemudian dicoba berjalan disekitar paris (mukhis akhadi: 2009)

Zaman minyak tampil secara perlahan dan hampir tidak terasa sejak tahun 1890-an setelah otomobil pertama muncuk dijalan raya. Dan ketika muncul pertama kali, otomobil itu dinilai tidak peraktis dan harganya yang mahal sehingga banyak orang yang ragu apakah kendaraan itu dapat bersaing dengan kereta kuda yang sudah lebih dulu digunakan masyarakat sebagai alat trasportasi. Tahun 1901 
semburan minyak untuk pertama kali terjadi di Spindletop Texas yang mengisyaratkan adanya ketersediaan minyak bumi dalam jumlah baesar yang

Motor pembakaran dalam pada umumnya dikenal dengan mana notor bakar torak, proses pembakaran berlangsung didalam motor bakar sendiri. Sehingga gas pembakaran yang terjadi, sekaligus berfungsi sebagai fluida kerja. Motor bakar torak memper gunakan beberapa silinder, didalamnya terdapat torak yang bergerak bolakbalik.

Campuran bahan bakar udara di dalam silinder motor Otto harus sesuai dengan syarat busi di atas, yaitu jangan terbakar sendiri. Ketika busi mengeluarkan api listrik yaitu pada saat beberapa derajat engkol sebelum torak mencapai TMA, campuran bahan bakar udara sekitar itulah yang mula-mula terbakar. Selanjutnya nyala api merambat ke segala arah dengan kecepatan yang sangat tinggi, menyalakan campuran yang dilaluinya sehingga tekanan gas didalam silinder naik, sesuai dengan jumlah bahan bakar yang terbakar.

\section{Definisi PGM-FI (Programmed Fuel Injection)}

Sistem PGM-FI (Programmed Fuel Injection) Sistem suplai bahan bakar dengan menggunakan teknilogi kontrol secara elektronik yang mampu mengatur. Pasokan bahan bakar dan udara secara optimum yang dibutuhkan oleh mesin pada setiap kendaraan.

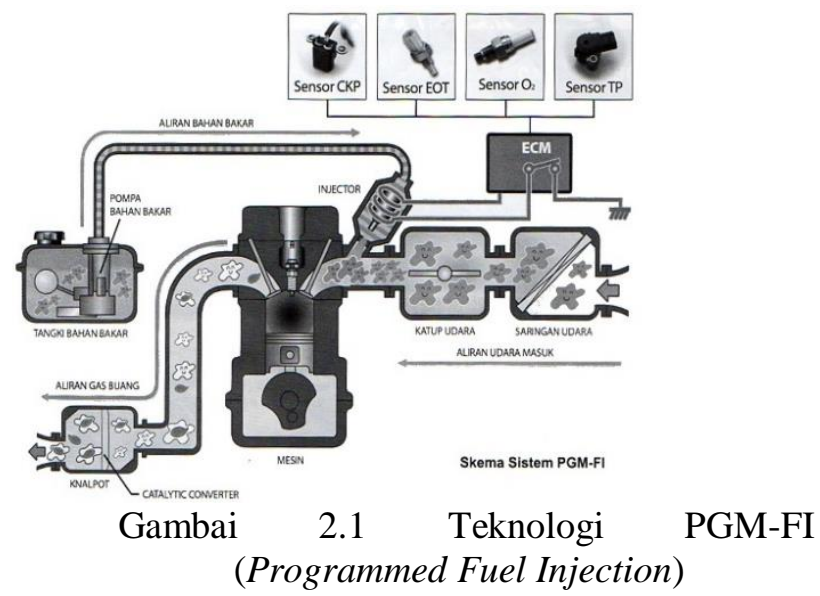

Sumber : Buku Panduan PGM-FI

Bahan bakar dari tangki di salurkan ke injektor secara bertekanan, selanjutnya sensor-sensor memberikan inputan informasi kepada ECM (Engine Control Module) terhadap kondisi mesin. Sehingga ECM (Engine Control Module)memerintahkan mencukupi digunakan sebagai bahan bakar kendaraan bermotor. (mukhlis akhadi: 2009)

\section{Kajian Umum Motor Bakar Torak}

injektor untuk menyemprotkan bahan bahar sesuai kebutuhan mesin.

\section{Keunggulan Sistem PGM-FI (Programmed Fuel Injection)}

Pada sistem PGM-FI jumlah baha bakar yang injeksikan oleh injector lebih presisi, sehngga campuran bahan bakar dan udara lebih homogen (merata) yang membuat pembakaran lebih sempurna. Karna pembakaran yang labih sempurna sehingga sepeda motor honda PGM-FI :

1. Lebih irit BBM.

2. Lebih bertenaga.

3. Mesin lebih mudah dihidupkan.

4. Lebih ramah lingkungan.

Selain itu komponen sistem PGM-FI pun tidak memerlukan pembersihan dan perawatan secara berkala, cukup dengan penggantian saringan bahan bakar setiap $48.000 \mathrm{~km}$ untuk perawatannya. Sehingga sistem PGM-FI lebih mudah perawatannya.

\section{Fitur-Fitur Teknik PGM-FI (Programmed Fuel Injection)}

\section{Injektor.}
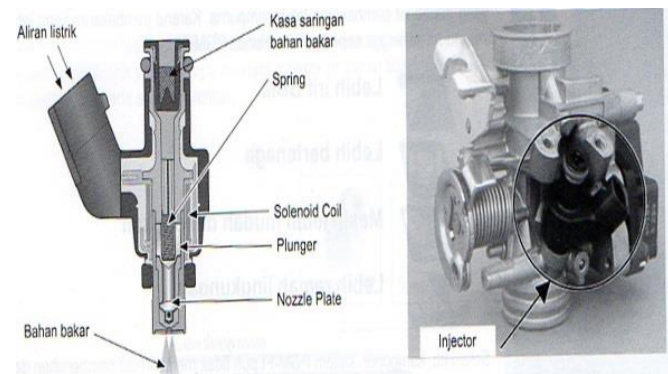

Gambar 2.2 Potongan Injektor Bahan Bakar (Sumber : Buku Panduan PGM-FI)

Injektor bekerja sesuai informasi dari ECM (Engine Control Module) untuk menyemprotkan bahan bakar yang dipasok dari pompa bahan bakar sesuai dengan kondisi motor.

a. Injektor terdiri dari komponen: kasa saringan bahan bakar, selenoit coil, plunger, spring dan nozzle plate

b. Pungsi dari injektor bahan bakar adalah menyemprotkan bahan bakar ke throttle body. 
c. Vulume injeksi bahan bakar yang disemprot disesuaikan dengan waktu bukan nozzle plate yang sesui dengan informasi yang dikirimkan dari ECM.

\section{Unit Pompa Bahan Bakar}

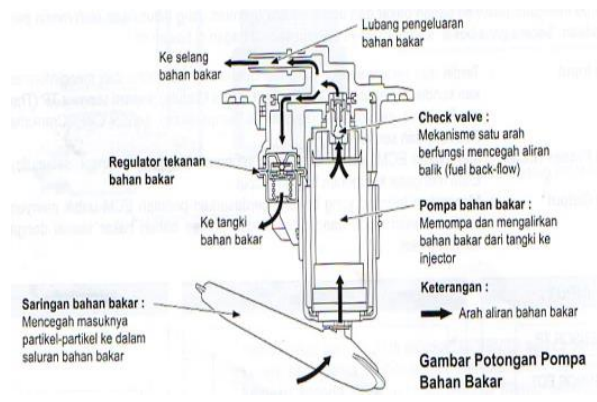

Gambar 2.3 Unit Pompa Bahan Bakar

(Sumber : Buku Panduan PGM-FI)

a. Pompa bahan bakar dipasang didalam tangki bahn bakar dan terdiri

dari saringan bahan bakar, pompa, regulator tekanan bahan bakar

b. Fungsi dari pompa bahan bakar adalah memompa dan mengalirkan bahan bakar dari tangki ke injektor dengan tekanan bahan bakar yang konstan $294 \mathrm{kPa}(3.0 \mathrm{Kgf} / \mathrm{cm} 2,43 \mathrm{psi})$

\section{ECM (Engine Control Module)}

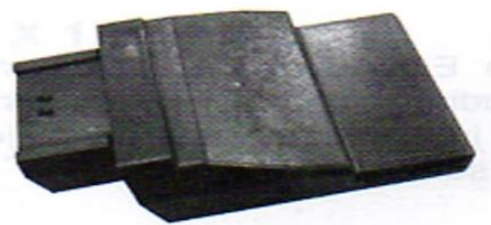

Gambar 2.4 ECM (Engine Control Modul)

(Sumber : Buku Panduan PGM-FI)

Fungsi dari ECM (Engine Control Modul) adalah menghantar sinyal dan mengatur durasi keluar berbahan bakar injektor pada kondisi yang optimal berdasarkan sinyal dari sensor-sensor dan mempertahankan tenaga agar tetap besar pada RPM rendah agar tidak terjadi detonasi pada mesin. Dan mengontrol kecepatan laju kendaraan pada mesin.

\section{Sensor CKP (crankshaft pisition)}

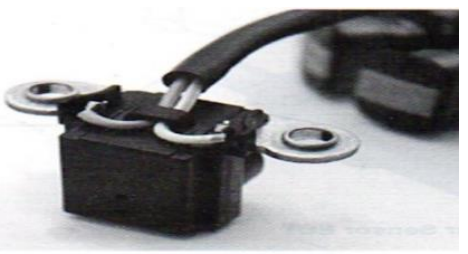

Gambar 2.5 sensor CKP (crankshaft pisition)

(Sumber : Buku Panduan PGM-FI)
Sensor CKP berfungsi mendeteksi putaran mesin sudut crankshaft kemudian informasi ini diperoses ECM untuk mengontrol jumlah dan waktu penginjeksian bahan bakar.

\section{Sensor TP (Throttle Position)}

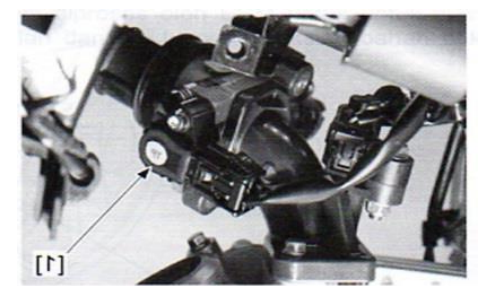

Gambar 2.6 Sensor TP (Throttle Position) (Sumber : Buku Panduan PGM-FI)

Sensor TP (Sensor Throttle Position) berfungsi untuk mendeteksi sudut bukaan Throttle Valve (katup kupu-kupu) kemudian informasi ini diproses oleh ECM untuk mengontrol jumlah dan waktu prnginjeksian bahan bakar sesuai sudut bukaan valve

\section{Sensor EOT (Engine Oli Temperature) \\ Sensor ECT (Engine Coolant Temperature)}
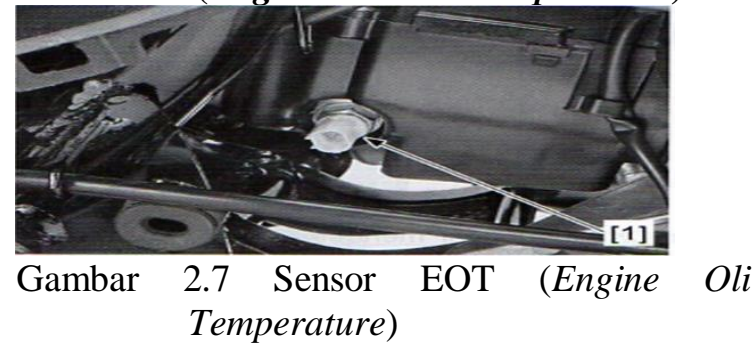

(Sensor ECT Engine Coolant Temperature) Sensor ECT dan EOT berfungsi untuk mendeteksi suhu mesin, kemudian informasi ini diproses oleh ECM untuk mengontrol jumah dan waktu penginjeksian bahan bahakar sesuai suhu mesin.

\section{Sensor O2 (Oksigen)}

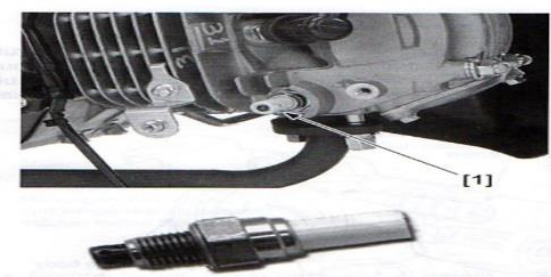

Gambar 2.8 Sensor O2

(Sumber : Buku Panduan PGM-FI)

Sensor $\mathrm{O} 2$ berfungsi untuk mendeteksi konsen trasi oksigen yang dikandung didalam gas buang kemudian informasi ini diperoses oleh ECM untuk mengontrol jumlah dan waktu penginjeksian bahan bakar yang tepat. 


\section{Garis Besar Sistem PGM-FI (Programmed Fuel Injection)}

Dengan menggunakan teknologi kontrol secara elektronik yang mampu mengatur pasokan bahan bakar dan udara secara optimum yang dibutuhkan oleh mesinn pada setiap keadaan. Secara garis besar, sistem pgm-fi bekerja seperti bagan dibawah ini :

1. Bagian input

Terdiri dari sensor-sensor yang mendeteksi kondisi motor dan menginformasikan kondisi tersebut ECM (Engine Control Module) seperti : sensor TP (Throttle Position) sensor EOT engine (Engine Oil Tempetature) sensor CKP (Crankshaft Positio) dan sensor O2 (oksigen).

2. Bagian proses ECM (Engine Control Module) merupakan ECM, yang memperoses informasi dari sensor-sensor selanjutnya ECM mengatur komponen bagian output.

3. Bagian Otput

Merupakan injektor, yang bekerja berdasarkan perinyah ECM (Engine Control Mudule) untuk menyemprotkan bahan bakar yang dipasok dari pompa bahan bakar sesui dengan kondisi motor.

\section{METODOLOGI PENELITIAN}

2.1 Kinerja Engine PGM-FI (Programmed Fuel Injection)

Dengan menggunakan metode interpolasi maka didapat torsi (T) dari daya efektif (Ne) untuk tiap putaran tertentu yang dicari dengan persamaan :

\section{Perhitungan Torsi}

Dengan menggunakan metode interpolasi maka didapat torsi (T) dari daya efektif $(\mathrm{Ne})$ untuk tiap putaran tertentu dengan melihat data pada kurva perfomance engine diatas, yang dicari dengan persamaan :

$$
\begin{aligned}
& N e=\text { T. } \omega=\frac{\text { T. } 2 . \pi \cdot n}{60.75}(\mathrm{~m} . \mathrm{kg} / \mathrm{s}) \\
& N e=\frac{\text { T. } n}{716,2} \quad \text { (PS) } \\
& \mathrm{T}=\frac{N e \cdot 716,2}{n}(\mathrm{~m} \cdot \mathrm{kg})
\end{aligned}
$$

\section{Tekanan Efektif Rata-Rata Motor (Pe)}

Tekanan Efektif Rata-rata Motor (Pe) terjadi didalam silinder dimana tekanan ini merupakan tekanan yang dapat mendorong torak sepanjang langkahnya untuk mendapatkan usaha per-siklus. Tekanan efektif motor dapat diperoleh dengan menggunakan rumus

$$
\mathrm{Pe}=\frac{T \times 2 \pi x 100}{V_{L} x Z x a}\left(\mathrm{Kg} / \mathrm{cm}^{2}\right)
$$

(Wiranto A, $1988: 33$ )

Dimana :

$\mathrm{Pe}=$ Tekanan efektif rata-rata motor $(\mathrm{Kg} / \mathrm{cm} 2)$

$\mathrm{T}=$ Momen putar $(\mathrm{Kg} . \mathrm{cm})$

$\mathrm{VL}=$ Volume Langkah $(\mathrm{cm} 3)$

$\mathrm{Z}=$ Jumlah silinder

$\mathrm{n}=$ Putaran motor $(\mathrm{rpm})$

$\mathrm{a}=$ Siklus perputaran bernilai 0,5 motor 4 langkah

\section{Penggunaan Bahan Bakar}

Untuk mencari perhitungan pemakaian bahan bakar (Gf) dapat menggunakan persamaan :

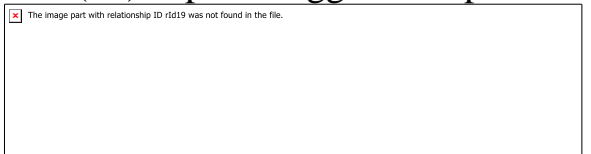

$$
\begin{aligned}
& \text { Dimana : } \\
& \mathrm{Ne}=\text { Daya efektif, }(\mathrm{PS}) \\
& \text { Qc = Nilai kalor bawah bahan bakar, menurut } \\
& \text { (SP. Sein, } 1980: 168) \text { besarnya } 10580 \mathrm{kkal} / \mathrm{kg}, \\
& \text { Gf = Pemakaian bahan bakar, }(\mathrm{kg} / \mathrm{jam}) \\
& \text { Hth }=\text { Efesiensi thermis } \\
& \text { r = Perbandingan kompresi }
\end{aligned}
$$

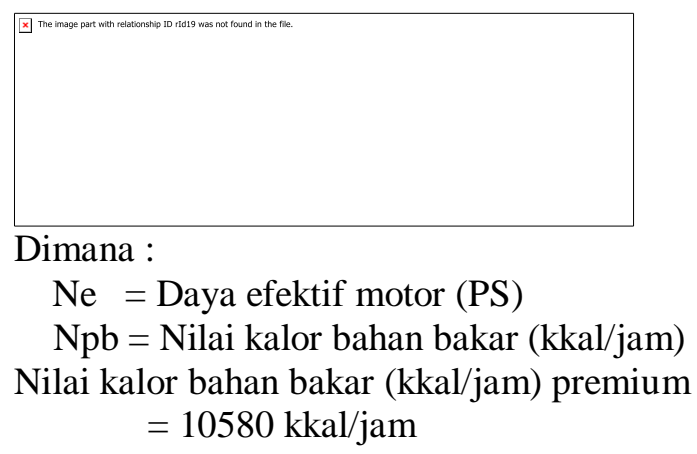

Setelah nilai Gf diketahui, maka nilai pemakaian bahan bakar spesifik dapat dicari dengan menggunakan rumus :

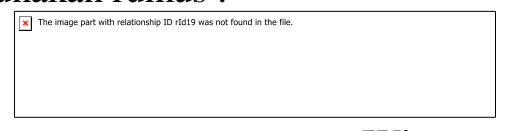

(Wiranto A, 1994:29)

\section{a. Daya Indikator (Ni)}

Daya indikator (Ni) diperoleh dengan rumus :

$$
\mathrm{Ni}=\mathrm{Ne} / \eta \mathrm{Mek}(\mathrm{PS})
$$

(Wiranto Arismunandar, $1988: 33$ )

Setelah daya indikator diperoleh, maka nilai permakaian bahan bakar spesifik indikator (Bi) dapat dicari dengan rumus: 


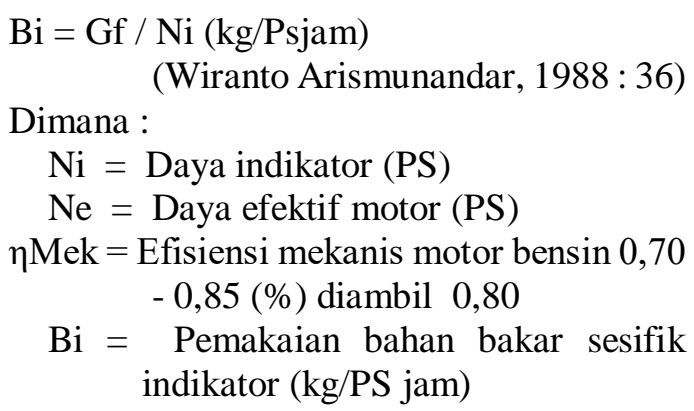

\subsection{Objek Penelitian}

Objek penelitian menggunakan motor sport CB 150R menggunakan mesin FGM-FI (Programmed Fuel Injection) menggunakan Dyno Tes

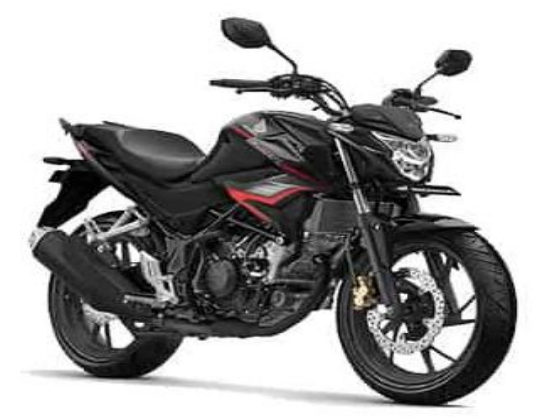

Gambar Motor CB 150R

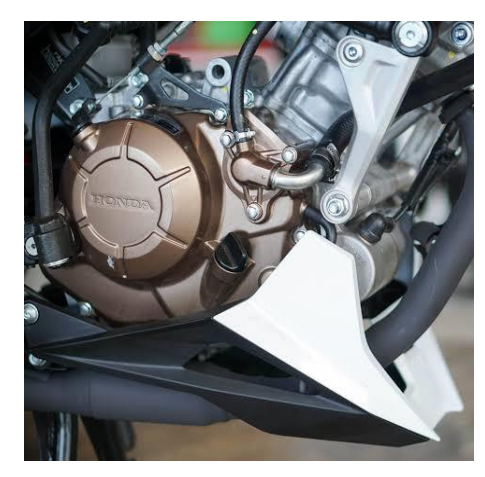

Gambar Mesin Motor CB 150R

Spesifikasi sepeda motor CB 150cc

Tabel 2.1 Tabel Spesifikasi Sepeda Motor CB 150R

\begin{tabular}{|l|l|}
\hline \multicolumn{2}{|c|}{ DIMENSI } \\
\hline Dimensi (P X L X J) & $2.019 \times 719 \times 1.039$ \\
\hline Jarak Sumbu Roda & $1.293 \mathrm{~mm}$ \\
\hline Jarak Terendah Ke Tanah & $169 \mathrm{~mm}$ \\
\hline Ketinggian Tempat Duduk & $797 \mathrm{~mm}$ \\
\hline Berat Kosong & $136 \mathrm{~kg}$ \\
\hline \multicolumn{2}{|c|}{ RANGKA } \\
\hline
\end{tabular}

\begin{tabular}{|c|c|}
\hline Rangka & $\begin{array}{l}\text { Diamond (Truss) } \\
\text { Trame }\end{array}$ \\
\hline Suspensi Depan & Teleskopik \\
\hline Suspensi Belakang & $\begin{array}{l}\text { lengan ayun dengan } \\
\text { suspense } \\
\text { tunggal (Sistem } \\
\text { Suspensi Prolink) }\end{array}$ \\
\hline Ukuran Ban Depan & 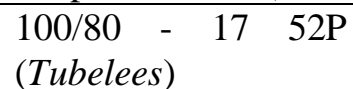 \\
\hline Ukuran Ban Belakang & 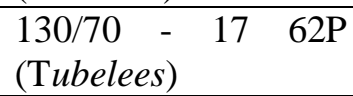 \\
\hline Rem Depan & cakram hidrolik \\
\hline Rem Belakang & cakram hidrolik \\
\hline \multicolumn{2}{|l|}{ MESIN } \\
\hline Tipe Mesin & $\begin{array}{l}4 \text { Langkah. DOHC. } 4 \\
\text { Katup }\end{array}$ \\
\hline Tipe Transmisi & Manual. 6 Kecepatan \\
\hline Sistem Pendingin Mesin & $\begin{array}{l}\text { Liquid Cooled With } \\
\text { Auto Fan }\end{array}$ \\
\hline Diameter X Langkah & $57.3 \times 57.8 \mathrm{~mm}$ \\
\hline Pola Pengoperan Gigi & $1-\mathrm{N}-2-3-4-5-6$ \\
\hline Kapasitas Mesin & $149.16 \mathrm{cc}$ \\
\hline Perbandingan Kompresi & $11.3: 1$ \\
\hline Daya Maksimum & $\begin{array}{l}12.4 \mathrm{Kw}(16.9 \mathrm{PS}) / \\
9.000 \mathrm{rpm}\end{array}$ \\
\hline Torsi Maksimum & $\begin{array}{l}13.8 \mathrm{Nm}(1.41 \mathrm{kgf.m}) \\
\text { / } 7.000 \mathrm{rpm}\end{array}$ \\
\hline Kopling & $\begin{array}{l}\text { Multiple Wet Clutch } \\
\text { Coil Spring }\end{array}$ \\
\hline Sistem Pelimasan & Wet \\
\hline Starter & pedal dan elektrik \\
\hline \multicolumn{2}{|l|}{ KAPASITAS } \\
\hline $\begin{array}{l}\text { Kapasitas Tangki Bahan } \\
\text { Bakar }\end{array}$ & 12 liter \\
\hline $\begin{array}{lll}\text { Sistem } & \text { Suplai } & \text { Bahan } \\
\text { Bakar } & & \\
\end{array}$ & injeksi (PGM-FI) \\
\hline $\begin{array}{ll}\text { Kapasitas } & \text { Minyak } \\
\text { Pelumas Mesin } & \\
\end{array}$ & 1.1 \\
\hline \multicolumn{2}{|l|}{ KELISTRIKAN } \\
\hline Tipe Batrai & MT Wet 12V 5Ah \\
\hline Sistem Pengapian & full transistorized \\
\hline
\end{tabular}

Tempat Dan Waktu Penelitian

Penelitian ini dilakukan di ULTRASPEEDRACING jl. Daan mogot, KM.6, Jakarta Barat (Samping Perum Casa Jardin) waktu penelitian pada bualan juni 2019.

\section{Alat Dan Instrumen Penelitian}


Alat yang dipakai yaitu jenis motor CB $150 \mathrm{cc}$ menggunakan alat Dyno tes merek DYNOmite.

\section{Pengamatan / Observasi / pengujian}

Untuk memperoleh data-data pengujian dilakukan dengan cara pengujian secara langsung dan juga dapat diperoleh data daya output pada setiap putaran dengan metode interpolasi.

Diagram Alir Penelitian

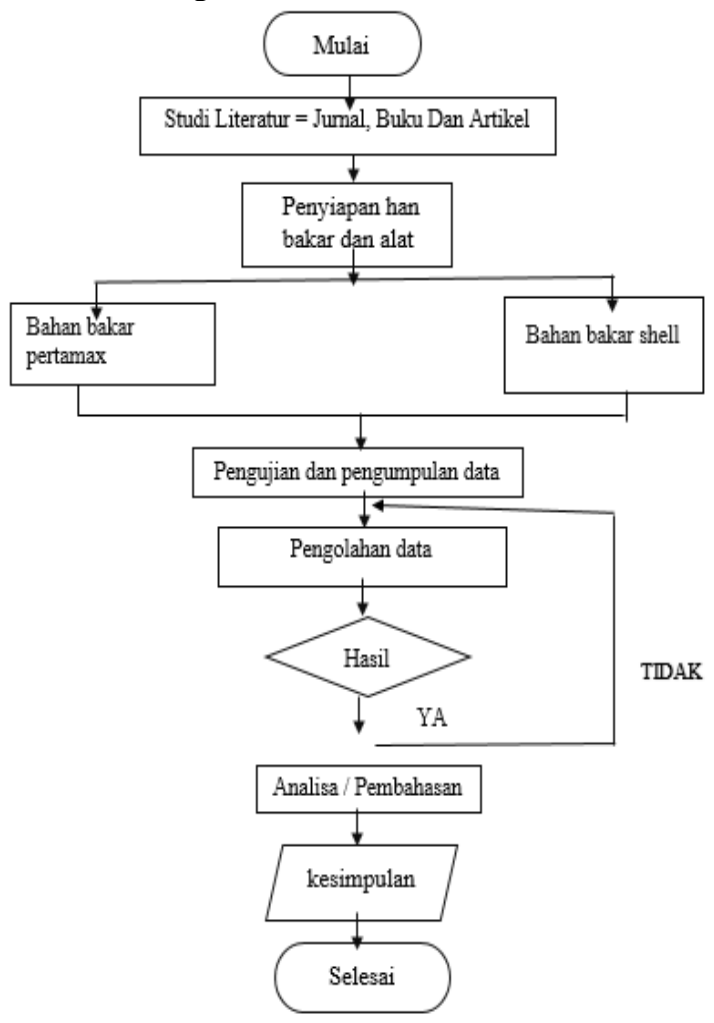

Gambar 3. Diagram Alir Penelitian

\section{HASIL DAN PEMBAHASAN}

\subsection{Perhitungan Performa Mesin PGM-FI} (Programmed Fuel Injection) Dari gambar kurva performance engine dapat diperoleh daya otput pada setiap putaran dengan metode interpolasi. Data-data sebagai berikut :

Tabel 3.2 Daya Otput Pada Setiap Putaran

\begin{tabular}{|l|l|l|l|l|}
\hline \multirow{2}{*}{$\begin{array}{c}n \\
(\text { RPM })\end{array}$} & \multicolumn{3}{|l|}{ Daya Output Pada PGM-FI } \\
\cline { 2 - 5 } & \multicolumn{2}{|l|}{ Pertamax } & \multicolumn{2}{l|}{ Shell Super } \\
\cline { 2 - 5 } & Power & Torsi & Power & Torsi \\
\hline 500 & 5,6 & 13,8 & 4,00 & 8,00 \\
\hline 1000 & 6,00 & 11,18 & 5,6 & 11,18 \\
\hline 1500 & 9,2 & 14,00 & 7,14 & 11,12 \\
\hline 2000 & 9,8 & 15,10 & 9,18 & 14,12 \\
\hline 2500 & 11,10 & 15,8 & 11,8 & 13,18 \\
\hline 3000 & 11,14 & 15,2 & 11,14 & 13,14 \\
\hline 3500 & 11,16 & 13,14 & 11,16 & 13,10 \\
\hline
\end{tabular}

\begin{tabular}{|l|l|l|l|l|}
4000 & 11,12 & 13,18 & 11,12 & 11,18 \\
\hline 4500 & 11,6 & 11,4 & 11,6 & 11,2 \\
\hline 5000 & 6,00 & 6,00 & 9,2 & 9,4 \\
\hline
\end{tabular}

\subsection{ANALISIS PERHITUNGAN \\ PERFORMANCE PROGRAMMED FUEL INJECTION (PGM-FI) SATU SILINDER 150 \\ CC Perhitungan Tellanan Efektif Rata-Rata Motor
(Pe)}

Maka tekanan efektif rata-rata motor untuk tiap tingkat putaran tertentu adalah sebagai berikut

Tabel 3..1Perhitungan tekanan efektif rata-rata motor

\begin{tabular}{|c|c|c|c|c|}
\hline $\begin{array}{c}\mathbf{N} \\
(\mathbf{R p m})\end{array}$ & $\begin{array}{l}\text { Torsi } \\
\text { Pada } \\
\text { Pertamax }\end{array}$ & $\begin{array}{l}\text { Pe Pada } \\
\text { Pertamax }\end{array}$ & $\begin{array}{l}\text { Torsi } \\
\text { Pada } \\
\text { shell } \\
\text { super }\end{array}$ & $\begin{array}{l}\text { Pe Pada } \\
\text { shell } \\
\text { super }\end{array}$ \\
\hline 500 & 13,8 & 115.552 & 8,00 & 66.986 \\
\hline 1000 & 11,18 & 93.613 & 11,18 & 93.613 \\
\hline 1500 & 14,00 & 117.226 & 11,12 & 93.111 \\
\hline 2000 & 15,10 & 126.437 & 14,12 & 118.901 \\
\hline 2500 & 15,8 & 132.298 & 13,18 & 110.360 \\
\hline 3000 & 15,2 & 127.275 & 13,14 & 110.025 \\
\hline 3500 & 13,14 & 110.026 & 13,10 & 109.690 \\
\hline 4000 & 13,18 & 110.360 & 11,18 & 93.613 \\
\hline 4500 & 11.6 & 95.456 & 11,2 & 93.781 \\
\hline 5000 & 6,00 & 50.24 & 9,4 & 78.709 \\
\hline
\end{tabular}

\section{Perhitungan Penggunaan Bahan Bakar}

Maka jumlah bahan bakar dan nilai bahan bakar spesifik yang dapat masuk ke dalam silinder pada tiap tingkat putaran tertentu adalah sebagai berikut:

Tabel 4. Perhitungan pemakaian jumlah bahan bakar dan nilai pemakaian bahan bakar spesifik yang digunakan pada tiap tingkat putaran tertentu 


\section{Analisa Perhitungan Data}

Untuk keseimbangan daya indikator yang terjadi, shell super menunjukan performa yang lebih baik dari pada pertamax yang disebabkan daya efektif yang terjadi pada shell super lebih baik di bandingkan pertamax begitu juga dengan nilai pemakaian bahan bakar spesifikasi shell super lebih baik dibandingkan pertamax. Yang disebabkan oleh perbandingan pengguna bahan bakar dan daya indikator yang terjadi. Dari penggunaan bahan bakar tersebut juga dapat dilihat bahwa shell super memiliki efisiensi yang lebih baik dibandingkan pertamax.
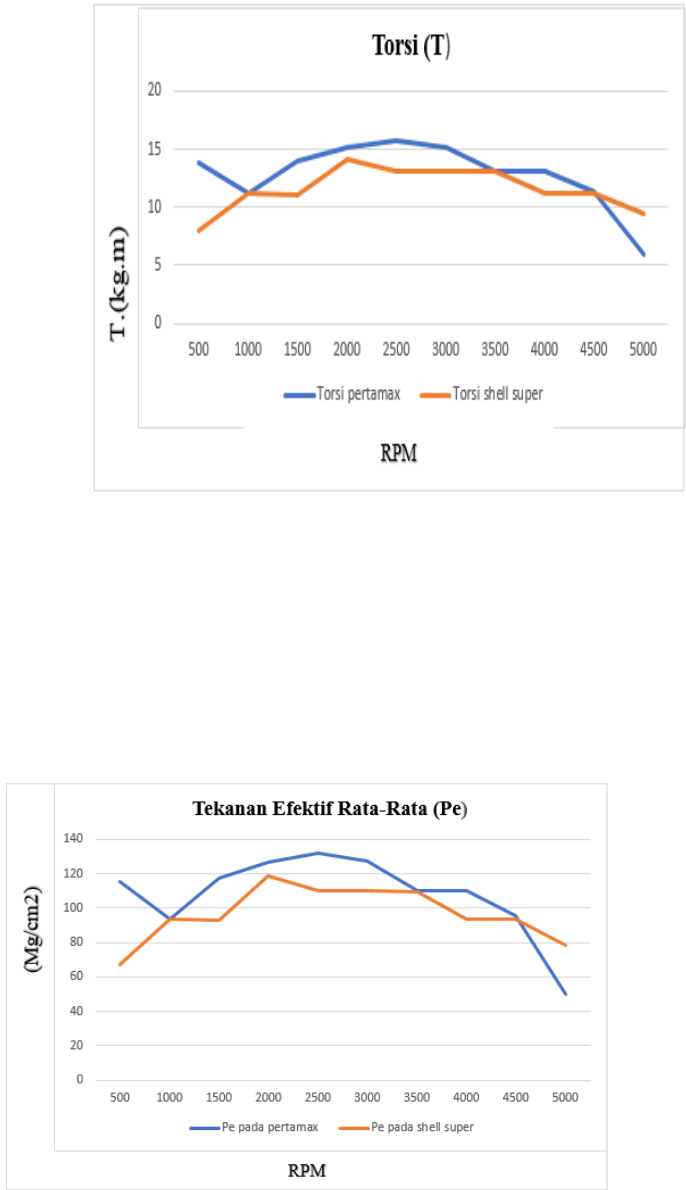

Gambar diatas memberikan gambaran tentang tekanan efektif rata-rata yang dapat dicapai pada shell super terjadi pada putaran $110 \mathrm{Mg} / \mathrm{cm} 2$ yang lebih tinggi dibandingkan pertamah hanya 130 $\mathrm{Mg} / \mathrm{cm} 2$ dari gambaran grafik perbandingan tekanan efektif ini dapat dilihat efektifitas dan efisiensi hasi dari bahan bakar shell super lebih lebih bagus dari pada pertamax yang hanya $120 \mathrm{Mg} / \mathrm{cm} 2$

\begin{tabular}{|c|c|c|c|c|c|c|}
\hline $\begin{array}{c}\text { Daya } \\
\text { output } \\
\text { pada } \\
(\mathrm{rpm})\end{array}$ & $\begin{array}{c}\mathrm{Gf} \\
\text { pertam } \\
\text { ax } \\
\mathrm{Ne} \\
(\mathrm{Pg} / \mathrm{ja})\end{array}$ & $\begin{array}{c}\mathrm{m}) \\
\text { perta } \\
\text { max }\end{array}$ & $\begin{array}{c}\mathrm{Be} \\
(\mathrm{kg} / \mathrm{PSj} \\
\text { am }) \\
\text { pertam } \\
\text { ax }\end{array}$ & $\begin{array}{c}\text { Daya } \\
\text { output } \\
\text { pada } \\
\text { shell } \\
\text { super } \\
\mathrm{Ne} \\
(\mathrm{PS})\end{array}$ & $\begin{array}{c}\text { Gf } \\
(\mathrm{kg} / \mathrm{jam} \\
\text { ) shell } \\
\text { super }\end{array}$ & $\begin{array}{c}\mathrm{Be} \\
(\mathrm{kg} / \mathrm{P}\end{array}$ \\
$\begin{array}{c}\mathrm{Sjam}) \\
\text { shell } \\
\text { super }\end{array}$ \\
\hline 500 & 5,6 & 0,67 & 0,12 & 4,00 & 0,48 & 0,12 \\
\hline 1000 & 6,00 & 0,71 & 0,12 & 5,6 & 0,68 & 0,12 \\
\hline 1500 & 9,2 & 1,09 & 0,12 & 7,14 & 0,85 & 0,12 \\
\hline 2000 & 9,8 & 1,17 & 0,12 & 9,18 & 1,09 & 0,12 \\
\hline 2500 & 11,10 & 1,32 & 0,12 & 11,8 & 1,41 & 0,12 \\
\hline 3000 & 11,14 & 1,33 & 0,12 & 11,14 & 1,33 & 0,12 \\
\hline 3500 & 11,16 & 1,33 & 0,12 & 11,18 & 1,33 & 0,12 \\
\hline 4000 & 11,12 & 1,32 & 0,12 & 11,12 & 1,32 & 0,12 \\
\hline 4500 & 11,6 & 1,36 & 0,12 & 11,6 & 1,38 & 0,12 \\
\hline 5000 & 6,00 & 0,71 & 0,12 & 9,4 & 1,12 & 0,12 \\
\hline
\end{tabular}

Grafik 4.1 Perbandingan Torsi Pada Setiap

Tingkat Putaran

Pada grafik diatas memberikan gambaran tentang experiment maksimum yang dapat dicapai pada shell super terjadi pada putaran yang lebih tinggi yaitu 10 Kg.m di Rpm 1000 dibandingkan pertamax Dari gambar grafik perbandingan torsi diatas dapat dilihat efektivitas dan efisiensi hasil kinerja shell super lebih baik dibandingkan peta

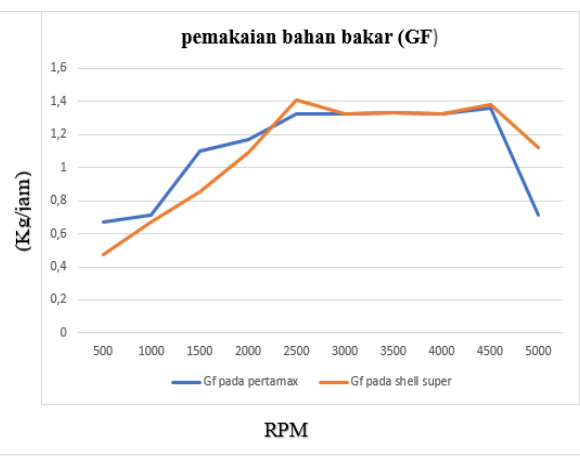

Gambar 4.3 Perbandingan Pemakaian Bahan Bakar Setiap Tingkatan Putaran

Grafik diatas diatas memberikan gambaran tentang penggunaan bahan bakar yang terjadi pada putaran yang sama dan bahan bakar shell super lebih baik $(0.5 \mathrm{Kg} / \mathrm{jam})$ dari pada pertamax yang lebih tinggi $(0.7 \mathrm{Kg} / \mathrm{jam})$. dan beban maksimum dari pertamax beban maksimumnya 1.3 di Rpm 2500 dan shell super 1.4 di Rpm 2500, Dari gambar grafik diatas perbandingan penggunaan bahan bakar ini dapat 
dilihat dari efektivitas dan efisiensi hasil kinerja bahan bakar.

\section{PENUTUP}

Berdasarkan analisa data dan pembahasan terhadap permasalahan yang telah ditetapkan, gambaran secara eksperimen tentang konsumsi bahan bakar ternyata shell lebih bagus dari pada pertamax. Dikaenakan torsi dari shell super $14 \mathrm{Kg} . \mathrm{m}$ di Rpm 2500 dan pertamax lebih rendah yaitu 15 Kg.m di Rpm. 2500 dan tekanan efektif rata-rata dari Shell super yaitu $110 \mathrm{Mg}$ di Rpm. 2500 dah hasil dari pertamax yaitu 130 Kg.m di Rpm 2500 dan dari hasil data. Tentu bahan bakar dengan pertamax dan shell super dengan RON 92 tentu shell super lebih bagus dibandingkan pertamax.

\section{DAFTAR PUSTAKA}

Arismunandar Wiranto (1988), "Penggerak Mula Motor Bakar Torak. Bandung penerbit ITB

Astra Honda Motor. (1995)."Modul buku panduan PGM-FI. (Programmed Fuel Injection)" Jakarta PT. Astra Honda Motor

Bambang Setyonno, Desmas Arifianto, Efrita Arfah Zuliari, Satria Mahdum Purbo Waseso. "Desain Dan Analisis Performasi Sistem Penggerak Purwarupa Kendaraan Hibrid Bertenaga Udara Dan Listrik "Bed 18" Menggunakan "Scotch Yoke Mechanism" Jurnal Iptek vol.23 No. 1 Mei 2019.

Fx. Sukidjo. Performa Mesin Pada Motor Empat Langkah Berbahan Bakar Premium Dan Pertamax. Forum Tenik vol.34 No.1, januari 2011.

Farid Majedi, Indah Puspitasari. "Optimasi Daya Dan Torsi Pada Motor 4 Tak Dengan Modifikasi Crankshaft Dan Porting Pada Cylinder Head". Jurnal Teknologi Terpadu vol.5 No. 1 April 2017.

Heywood Jhon B (1998), Internal Combustion Engine Fundamentals", McGraw Hill Book Company, New York

I Nyoman Sutantra Bambang Sampurno (2010), "Teknologi Otomotif". Penerbit Guna Widya, Surabaya

James D. Halderman, Jim Linder (2009). "Automotive Fuel And Emissions Control System" (second edition) : Prentice Hall Upper Saddle, New Jersey Columbus, Ohio

Khovakh (1976). "Motor Vehicles Engine". Moscow. Mr.Publiser 